\title{
An exploration of discoursal identity: The rhetoric of narrative writing
}

\author{
Inna Livytska
}

DOI: 10.18355/XL.2021.14.02.12

\begin{abstract}
The paper aims at disclosing the process of writer identity enactive construal in narrative writing. Three constituent parts of identity discoursal construction in the narrative are social semiotics as a reflection of the social environment, cultural identity theory as the embodiment of cultural choices and preferences, and pragmatics (Charles S. Peirce). The following research questions have been formulated: (1) What is the nature of identity construction? (2) What rhetorical factors influence identity construal in narrative discourse? By providing a step-by-step analysis of thematic structure, the paper conducts a discourse analysis of narrative episodes in terms of Agent, Process, and Medium triad (Halliday, 1973), reflecting the mechanisms of reader's manipulation with information as a dynamic semiotic process of interpretation, limited by a final interpretant.
\end{abstract}

Key words: narrative, subjectivity, world disruption, index, symbol, pragmatic features

\section{Introduction}

The notion of identity has long been the object of analysis in the humanities but conventionally in the domain of psychology and philosophy. With the anthropological scientific turn in the humanities and formation of psycholinguistics, cognitive and social linguistics in the middle of the XXth century, the notion of identity and its discoursal manifestations have rightly entered the terminological apparatus of language sciences, calling for more interdisciplinary research regarding the process of its construction. Writer identity construal today is seen as one of the most essential practices of human cultural and social communication. The nature of the social component of written communication ascribes any text a place of social interactions of the author with the imaginary reader, where the writer's and reader's identities are negotiated and concurrently created. Namely socio-cultural approach postulates writing as a kind of symbolic semiotic mediation helping the agentive individuals achieve a certain communicative aim (i.e. social positioning, point of view, ideational attainment, perlocutionary effect, etc. (Zhao, 2014:453).

Cultural constructivism, in its turn, asserts inseparability of the identity from ideational and cultural background, from the writer's personal beliefs, expectations, and self-esteem. Thus, writing is viewed as space, where linguistic knowledge, cognitive skills, and creativity meet to mold a unique cognitive image of writer's discoursal identity as a 'discoursal self' (Ivanic, 1998: 25) and its representation in the text.

Narrative writing as a special type of written genre, where the notion of mediation has been stated as one of the universals (Fludernik, 1996) connects the writer and 'the implied reader' in the intersubjective and interpersonal dialogue, where two socio-cultural symbolic systems meet, delimiting the opposition of Self and the Other in the process of interpretation. Available differences in the sociocultural paradigm of Self and those of the Other become essential drivers or 'catalyzers' (in Roland Barth's terms) of discourse dynamics, the distribution, and their functional particularities in narrative discourse have been little investigated so far. Therefore, the topicality of the current study is defined by the necessity to trace

XLinguae, Volume 14 Issue 2, April 2021, ISSN 1337-8384, eISSN 2453-711X 
the connection between the narrative structure and the knots of the reader's engagement into the text, where subjectivity arises.

Consequently, the hypothesis of this study is based on the assumption that the discoursal construction of identity in narrative writing is grounded in the indexes of subjectivity, reflecting unusual or surprising chunks of personal experience of the writer and serving the points of navigation for discoursal identity construction.

The purpose of the paper is to trace linguistic, and rhetoric means of narrative identity construction in the symbolic system of narrative situations. The following research questions have been formulated: (1) What is the nature of subjectivity and its role in identity construction in narrative studies? (2) What rhetorical and linguistic factors influence the identity construal in narrative discourse?

To reach these objectives, the article will commence with the literature review section, describing a current state of research on the identity and social-constructivist theory. Then it will proceed to the Methodology section and Results and Discussion parts and will crown with the Conclusions.

\section{Identity in writing}

The notion of identity is not easy to define due to its abstract character and psychological grounding, which caused a multiplicity of uses and overlapping definitions (Casanave, 2002). The problem is that the very notion of identity has been conventionalized to be defined through other abstractions such as 'self', 'persona', 'position', 'subject' (Ivanic, 1998), which themselves are very context-dependent notions and, correspondently, don't make clear the notion of identity per se. The basic meaning of identity, coming from general psychology, is reflected in the sense of the self at the definite episode of living, which is in itself a rather dubious statement. The situation becomes even worse when the fuzziness of the notion 'self' is rendered to the derivatives like 'self-esteem', 'self-actualization', 'self-representation', turning them into even more incomprehensible notions. The reason for this traditional approach was long time adherence to the static view on human individuality, as a 'singular self' (Ivanic, 1998: 15), which has been subjected to criticism by analytic psychologists (Matsuda, 2015) and led to its reformulation into 'a complex, contradictory and multifaceted dynamic notion (Norton, 1997: 419; Ivanic, 1998: 10), construed through writing (Burgess, Ivanic, 2010).

Hence writing is an 'act of identity' (Ivanic, 1998); the argument about its discoursal nature is more than relevant here. Conceptualization of the writer's identity by Roz Ivanic outlined the following strands for self-hood: autobiographical self, discoursal self, authorial self, and possibilities for self-hood in the social-cultural contexts and institutional contexts (Ivanic, 1998: 25-27). Since in narrative writing, the authorial self is connected with the author's participation in the storyline in the status of the narrator, it can have different degrees of involvement on the nexus of exteriorization and interiorization. Following that, we differentiate between homodiegetic and heterodiegetic narrators by tracing their presence in subjective deictic markers, changing the perspective of the whole story.

Discoursal self in writing emerges from the text and is constructed through the symbolic representation of values, beliefs, and social norms, mirroring the period and its social and cultural particulars (Ivanic, 1998:25). According to Ivanic, in the discoursal self-analysis, we deal with the intentionally created and adopted role or 'persona' and its 'voice', constructed as a result of foregrounding (i.e. managing the focus of reader's perception).

Fictionality of narrative writing builds its credibility on the correlation between real and possible, which is measured by the perlocutionary effect of the utterance (Halliday, 1973). Possibility and probability of meaning are directly bound to 'the autobiographical self' of the writer, encompassing writer's morality (i.e. Aristotelian ethos) and influencing the flow of discoursal self-revealing. The 
rhetorical ethos of the writer is unconsciously manifested in the choice of the topics, the manner of argumentation, etc., influences the writer's credibility (Cherry, 1988: 268; Matsuda, 2015: 151), and thus is an important component of the writer's identity from the position of rhetoric discourse analysis.

Though different manifestations for self-hood, outlined above, can be researched from a bottom-up and top-down approach, they rarely if ever function in isolation. While it is the dynamic process of discoursal identity construction which can be traced on time scales (Burgess, Ivanic, 2010), it is important to fix the semiotic knots of subjective meaning arousal in the narrative text proper, moving from symbols and connotations and their distribution in small discourse units (further "SDUs"), represented by clauses.

\section{Methodology}

This study is based on the analysis of a written corpus comprised of randomly selected narrative episodes with the autobiographical type of narration (i.e. first-person narrative situations where the narrator is one of the agents of the plot development) taken from a newly compiled corpus of Victorian fiction (Riddel, et.al, 2019). The corpus data consisted of 997,730 tokens; 853,997 words; 27,996 sentences; 8 documents. To define the location of deictic centers in the narrative episodes the corpus has been scanned by Sketch. Engine tool to obtain preliminary data on personal pronouns frequency and their combinability (Personal pronoun +Verb; Possessive Personal Pronoun+Verb). Then the search has been limited to the cases with a first-person singular personal pronoun, and the most frequently used verbs in Pronoun+Verb groups have been identified and distributed according to different types of predication. This initial stage of research gave important material for understanding the level of agency of the first person pronoun judging from its combinability with action verbs. Further applied semiotic analysis of the indices of subjectivity was necessary for tracing the lingua-pragmatic potential of 'discoursal self' construction in the narrative. To define the index and its symbolic function in narrative identity construction, as well as types of relations between the signs, the primary model of abductive reasoning Charles Peirce (Fann, 1970) and rhetoric structure analysis have been utilized. It helped to identify the episodes with higher levels of subjectivity, provoked by hypothesizing on the side of the interpreter.

\section{Results and Discussion}

The results of the preliminary analysis of personal pronouns distribution showed the overall frequency of first-person pronouns in the singular as 11, 767. Together with the personal pronoun in objective case 'me' $(3,649)$ and possessive pronouns 'my' (6. 873) and 'mine' (25) and the reflexive pronoun 'myself' (590) it constituted in total 22,304 out of 98,939 cases of use. Table 1. represents the distribution of the personal pronouns in the corpus. For a general account of pronouns used in the corpus, see Appendix. 
Table 1: Distribution of the personal pronouns in the Victorian corpus

\begin{tabular}{llll}
\hline & $\begin{array}{c}\text { Pronouns } \\
\text { lemma }\end{array}$ & Frequency \\
\hline I & & 11,767 & \\
My & & 6,873 & \\
Me & & 3,649 & \\
Myself & & 590 & \\
Mine & & 25 & \\
& Total & & 22,304 \\
\hline
\end{tabular}

Among the analyzed pronouns in narrative episodes, the personal pronoun I was the most frequently used type of pronoun, which was explained by the dominating type of narration in each narrative episode. The range of functions performed by the pronoun in the corpus under scrutiny was the following:

- I' as a subject,

- 'I' as an object

- I' in prepositional phrases

- Pronominal possessors of 'I' (Sketch.Engine).

The most common verbs used with 'I' as a subject of the sentence were deceive, love, think, be, (see Appendix) which could have pointed at the agency type performed by the subject, as well as providing a general thematic sketch on the topics of narration. As seen from the concordance function in Sketch.Engine tool, the verbs are used not in the direct meaning of deception, as an act of fraudulent behavior, but are embedded in intimate monologues of the narrator with rhetorical questioning (cf. Appendix):

Example 1. With increased violence, he exclaimed, 'Have I deceived myself here too? Therese, did you not prefer me?' (doc \#2)

Example 2. But no, I deceive myself, they were tears of aversion and anger. (doc \#5). The unusual connotation has been observed regarding the lexeme love, which shows the concordance of the corpus, is used concerning inanimate abstract notions: love to look at the picture or love law, etc. In comparison with the modifiers of 'love,' the following conceptual representation can be drawn (see Table 2).

Table 2. Word Sketch 'LOVE' as a noun (restricted to the first ten positions vs.379 as a verb see Appendix).

\begin{tabular}{|lll|}
\hline \multicolumn{2}{|c|}{ Lemma 'LOVE' } \\
\hline Modifiers of 'love' & 'Love' As Object & 'Love' and /Or \\
& Mortify his love & Tenderness and love \\
\hline Illicit love & Tell the love & Marriage and love \\
\hline Mutual love & Return love & Pardon and love \\
\hline Of true love & Feel love & For love or money \\
\hline Parental love & Make love & Love and sober joy \\
\hline Filial love & Be (this is not love) & Love and regret \\
\hline Fraternal love & Have love & Love and resentment \\
\hline Almighty love & & Taste and gentle love \\
\hline Unbounded love & & Love, gratitude \\
\hline Dear love & & Love and honor \\
\hline Dignified love & &
\end{tabular}


This initial stage of research gave a general understanding of key words characterizing different agents of the narrative storyline, judging from its combinability with action verbs. The next stage of the analysis revealed the knots of plot development, where the subjectivity of the narrative identity arises. As has been mentioned in the methodology section, to trace identity construal, one has focused on the distribution and sequence of indices in small discourse units (further 'SDUs"), represented by clauses. To construct and perform agentive and authoritative subjectivities in an imaginative fictive context, I-narrator applies the range of poetic techniques, enhancing the reader's engagement with the text, which can be observed in step-by-step inter-clause relation analysis.

The clause is defined in theoretical syntax as any word group, with or without predication, centered around the verb, and when there is no verb - the group is centered around a linking verb (RST: Rhetorical Structure Theory Website). The types of rhetorical relations, which lie in the basis of narrative coherence, navigate the development of the writer's argument on the global and local levels (Palatovskaia, 2014). While the main function of the rhetorical relations is to create cohesive and coherent discourse, marking the type of relations within a local and global narrative structure will provide an insight into the process of identity construal.

The findings from the study of SDUs on the local level (e.i. on the level of topic coherence) showed that markers of subjectivity play a key impact on the construction of narrative identity in the following set of relations between the clauses: asymmetrical and symmetrical.

While asymmetrical rhetorical relations represent the subject-matter of discourse and ways of event presentation, they are constituted out of the nucleus (main clause) and satellites (subordinate clauses), building a certain hierarchy within the global narrative structure. The general types of rhetorical relations are summed in Table 3.

Table 3: Rhetorical relations in the Rhetoric Structure Theory (adapted from Palatovskaia, 2014: 90).

\begin{tabular}{|c|c|c|}
\hline Type & $\begin{array}{l}\text { Assymetrical mono-nuclear relations (consisting of a } \\
\text { single nucleus and a single satellite); }\end{array}$ & $\begin{array}{l}\text { Symmetrical multi-nuclear } \\
\text { relations } \\
\text { (link together a set of entities } \\
\text { of equal status, }\end{array}$ \\
\hline Objective & $\begin{array}{l}\text {-Elaboration; } \\
\text {-Circumstance; } \\
\text {-Solutionhood } \\
\text {-Causal cluster relations: volitional cause, volitional } \\
\text { result, non-volitional cause, non-volitional result, } \\
\text { purpose; } \\
\text { - Condition; } \\
\text { - Interpretation; } \\
\text { - Evaluation; } \\
\text { - Otherwise (alternative); } \\
\text { - Restatement (paraphrasing); } \\
\text { - Enumeration (listing); } \\
\text { - Resume (summary). }\end{array}$ & $\begin{array}{l}\text {-Joint, } \\
\text {-Sequence, } \\
\text {-Contrast }\end{array}$ \\
\hline Presentational & $\begin{array}{l}\text {-Motivation; } \\
\text {-Evidence; } \\
\text {-Justification; } \\
\text { - Antithesis; } \\
\text { - Background; } \\
\text { - Enablement; } \\
\text { - Concession. }\end{array}$ & \\
\hline
\end{tabular}


Hereby we will comment in detail on the several first clauses of each narrative episode with autobiographical 'I' in the function of the narrator. One of the major points in identity analysis is transitivity, mood, and thematic structure, which can be paralleled by the analysis of agency, process, and medium (Halliday, 1973).

\section{Example 1.}

Episode 1. From 'Semi-Attached Couple' by Emily Eden (1869).

There was only Helen left. Helen, so beautiful, so gentle, so light-hearted -the pride of her parents, the petted friend of her sisters, the idol of her brother, and loving as warmly as she was beloved. Yes, I knew Helen from her childhood and had thought that such a gentle, gay creature could never be touched by the cares and griefs that fall on the common herd. "It was very much to the credit of my benevolence, though not of my judgment," as Sneer says. Why was she to escape? I do not wish to be cynical, but if a stone is thrown into our garden, is it not sure to knock off the head of our most valuable tulip? If a cup of coffee is to be spilled, does it not make a point of falling on our richest brocade gown? If we do lose our reticule, does not the misfortune occur on the only day on which we had left our purse in it? All these are well-known facts, and, by parity of reason, was it to be expected that anyone, so formed as Helen was to enjoy as well as to impart happiness, should escape the trials that ought to have fallen on the peevish and the disappointed - on me, for instance, or such as me?

The division of clauses into rhetorical groups in Example 1 is aimed at identifying a verb group or a linking verb in the local discourse structure. Thereby the episode is semantically split into three parts: [description of Helen] +interrogation: Why was she to escape? + [description of the possible misfortunes of life destiny for Helen] + [framing the episode with self-reference] (see Table 4.)

Table 4. Agency, process, medium correlation in the narrative episode \#1.

\begin{tabular}{llll}
\hline Part 1 & $\begin{array}{l}\text { Agency } \\
\text { Helen }\end{array}$ & $\begin{array}{l}\text { Process } \\
\text { was left } \\
\text { was beloved }\end{array}$ & $\begin{array}{l}\text { Medium } \\
\text { visual } \\
\text { represented by narrating 'I' }\end{array}$ \\
Part 2 'I'- narrator-reflector & $\begin{array}{l}\text { knew } \\
\text { thought } \\
\text { don't wish }\end{array}$ & $\begin{array}{l}\text { memory } \\
\text { mental model } \\
\text { contemplation }\end{array}$ \\
Part 3. 'I' - narrator performer & residue & residue \\
\hline
\end{tabular}

The agency analysis in the narrative episode\# 1 reveals Agency-ProcessMedium encoding of the verbal groups in three consecutive parts changing from the passive agency of Helen, expressed by passive voice constructions and indirect characterization of narrating 'I' through visual semiotic mode, and then moving to a more dynamic agency of the narrating 'I' embedded in the verbal groups in active voice and emotional interrogations concerning the subject-matter of the narrative. The final clause performs a framing function by returning the narrative to the agency of Helen and then, unexpectedly, turning the focus on the narrating ' $I$ ' as the subject of the future events.

The distribution of rhetorical groups shows the following rhetorical pattern of Part 1 and Part 2 in narrative episode \#1: 
Table 5: Rhetorical groups and functions in Part 1 and Part 2 of the narrative episode \#1.

\begin{tabular}{|l|l|}
\hline $\begin{array}{l}\text { 1. There was only Helen left. } \\
\text { 2. Helen, so beautiful, so gentle, so light- } \\
\text { hearted-the pride of her parents, } \\
\text { 3. the petted friend of her sisters, the idol of } \\
\text { her brother, and loving as warmly as she } \\
\text { was beloved }\end{array}$ & Elaboration $|2-3|$ \\
\hline \begin{tabular}{l} 
4. Yes, I knew Helen from her childhood, \\
\hline 5. and had thought
\end{tabular} & Evidence $|4|$ \\
\hline $\begin{array}{l}\text { 6. that such a gentle, gay creature could } \\
\text { never be touched by the cares and griefs }\end{array}$ & Volitional cause $|6|$ \\
\hline \begin{tabular}{l} 
7. that fall on the common herd. \\
\hline $\begin{array}{l}\text { 8. It was very much to the credit of my } \\
\text { benevolence, }\end{array}$
\end{tabular} & Cause $|8|$ \\
\hline 9. though not of my judgment' & Concession $|9|$ \\
\hline \begin{tabular}{l} 
10. as Sneer says \\
\hline
\end{tabular} & Joint $|10|$. \\
\hline
\end{tabular}

As evident from the rhetorical functions shows how rhetorical units connect the components of the local rhetorical structure, moving further to the global parts (paragraphs, topics, etc.). Presented here, the rhetorical structure can be interpreted in other alternative relations, albeit all SDUs (clauses) will serve the cohesive function on the global structure of discourse.

In part 3 of narrative episode \#1, as it has been demonstrated in Table 4., the narrator changes his status from the reflecting agency into performing one. On the textual level, this process is emphasized by the gradation of interrogative questions of highly emotional lexical strata, causing an effect of suspense, which holds till the end of the paragraph, be solved only with the framing pronoun 'me, or such as me', signaling about a possible causative effect of the current situation with 'Helen' and the connection with the narrating 'I'. The rhetorical functions of the clauses have the following distribution summed in Table 6 .

Table 6: Rhetorical groups and functions in Part 3 of the narrative episode \#1.

\begin{tabular}{|c|c|}
\hline 11. Why was she to escape? & Interpretation $|11|$ \\
\hline 12. I do not wish to be cynical; & Non-volitional cause $|12|$ \\
\hline $\begin{array}{l}\text { 13. But if a stone is thrown into our } \\
\text { garden, }\end{array}$ & $\begin{array}{l}\text { Contrast |13|- } \\
\text { Elaboration |13-19| }\end{array}$ \\
\hline $\begin{array}{l}\text { 14. is it not sure to knock off the head of } \\
\text { our most valuable tulip? }\end{array}$ & Non-volitional result |14| \\
\hline 15. If a cup of coffee is to be spilled, & Non-volitional cause $|15|$ \\
\hline $\begin{array}{l}\text { 16. does it not make a point of falling on } \\
\text { our richest brocade gown? }\end{array}$ & Non-volitional result $|16|$ \\
\hline 17. If we do lose our reticule, & Non-volitional cause $|17|$ \\
\hline
\end{tabular}

XLinguae, Volume 14 Issue 2, April 2021, ISSN 1337-8384, eISSN 2453-711X 


$\begin{array}{ll}\begin{array}{l}\text { 18. does not the misfortune occur on the } \\ \text { only day }\end{array} & \text { Non-volitional result }|18| \\ \text { 19. on which we had left our purse in it? } & \text { Elaboration }|19| \\ \text { 20. All these are well-known facts, and, Evaluation }|20| \\ \text { by parity of reason, } \\ \text { 21. was it to be expected that anyone, so } \\ \text { formed as Helen } \\ \begin{array}{ll}\text { 22. was to enjoy as well as to impart } \\ \text { happiness }\end{array} \\ \begin{array}{l}\text { 23. should escape the trials that ought to } \\ \text { have fallen on the peevish and the } \\ \text { disappointed - on me, }\end{array} \\ \begin{array}{l}\text { 24. for instance, } \\ \text { or such as me? }\end{array}\end{array}$

Considering the general distribution of the rhetorical clauses and their functions within the first narrative episode leads to the initial conclusion about controversial results caused by the interpreter's subjective judgment. This is what one would expect dealing with the Theory of Rhetoric Structure, while the criticism of the concept lies mainly in the absence of one correct interpretation of the rhetorical relations in discourse (Matsuda, 2015; Ivanic, 1998). The fact, which can be seen as a limitation of a structuralist approach to text analysis, in the context of socio-cultural approach becomes a favor as it mirrors the dynamic potential of the identity to evolve within new contexts and the circles of interpretation in a global discourse structure. It goes in line with the Peircian concept of abductive reasoning, which is employed by the reader while decoding and hypothesizing about possible plot development on the brinks of contra factual thinking and semantics of possible worlds (Thomas Pavel). From these premises, the rhetoric analysis might seem viable, as the endless loop of narrative interpretation is limited by the final interpretant (Peirce, 1967) or habit, grounded on the denotations and moving from index to symbol and vice versa.

\section{Conclusion}

Critical analysis of research on identity in written discourse revealed the controversial nature of constructivism and formal approaches to personality, considering 'self' an invariable constituent of the human identity. Being subjected to criticism from the positions of enactivism and semiotics, identity in writing nowadays is characterized as a dynamic socio-cultural meaning-making of 'self' in the discursive space, through language, knowledge, and symbolic mediation to achieve a desired social positioning. Narrative writing is seen here as an identity act, where writer's and reader's subjectivities meet in the process of interpretation. The study proved the hypothesis that the discoursal construction of identity in narrative writing is grounded in the indexes of subjectivity, reflecting unusual or surprising chunks of personal experience of the writer and serving the points of navigation for discoursal identity construction. Simultaneously, the research has revealed some limitations of the Rhetoric Structure Theory regarding narrative identity analysis. The main reason for that is the semantic variability of possible interpretations of rhetoric relations among the smallest discourse units (SDPs). Coupled with systematic functional linguistics and social semiotics frameworks, the current paper managed to trace the identity construction within narrative episodes of fictional first-person narrative situationssuch combination of methods together with corpus analysis of Common Library 1.0.: A Corpus of Victorian novels with Sketch. Engine tool helped to define the denotative layer in the form of wordlists, noun and verb groups, their combinability, and frequency of use. 
Deictic centers serve as navigating knots on the way to enactive meaningmaking, scattered in the narrative in a certain sequence and frequency to enhance the suspense or reversely, slow the pace of narration (which has been proved by the dominance of rhetorical patterns of elaboration and voluntary cause and result within the narrative episode). The perspectives of further research lie in the sphere of narrative identity investigation within the socio-cultural semiotic approach to trace the fields of the regularity of the subjectivity emergence on the material of modern and post-modern fiction as well as cross-cultural research of narrative identity.

\section{Bibliographic references}

BURGESS, A. - IVANIC, R. 2010. Writing and Being Written: Issues of Identity Across Timescales. In: Written Communication, vol. 27, n. 2, pp. 228-255. ISSN 0741-0883.

CASANAVE, C.P. 2002. Writing games: Multicultural case studies of academic literacy practices in higher education. Mahwah. NJ: Erlbaum ISBN 0-8058-3531-8.

CHERRY, R. 1988. Ethos vs. Persona: Self-representation in written discourse. In: Written Communication, vol. 5, n.3, pp. 251-276. ISSN 0741-0883.

FANN, K.T. 1970. Peirce's Theory of Abduction. The Hague: Martinus Nijhoff. ISBN 978-94-010-3163-9.

FLUDERNIK, M. 1996. Towards a 'Natural' Narratology, London: Routledge. ISBN 10-0415124824.

HALLIDAY, M.A.K. 1973. Explorations in the Functions of Language. London. England: Edward Arnold. ISBN 0713117389.

HAYES, J.R. - FLOWER, L.S. 1981. A Cognitive Process Theory of Writing. In: College Composition and Communication, vol. 32, pp.365-387. ISSN 0 010096X

IVANIC, R. 1998. Writing and Identity: The Discioursal construction of identity in academic writing. Studies in Written Language and Literacy. Amsterdam, Netherlands: John Benjamins. ISBN 9781556193231.

MATSUDA, P. 2015. Identity in Written Discourse. In: Annual Review of Applied Linguistics, vol.35, pp.140-159. ISSN 02671905.

NORTON, B. 1997. Language, identity and the ownership of English. In: TESOL Quarterly, vol. 31, pp. 409-421. ISSN 00398322.

PALATOVSKAIA, Y.V. 2014. Discursivnyi analiz i t'eoriia ritoricheskoi structure. In: Naukovyi visnyk kafedri UNESKO Kiivs'kogo nacionalnogo lingvisticnogo universitetu. Filologia, vol. 29, pp.89-95. ISSN 2411-5991.

PEIRCE, C. S. 1967. Manuscripts in the Houghton Library of Harvard University. Amherst: University of Massachusetts Press. Available online: https://library.harvard.edu/collections/charles-s-peirce-papers.

RHETORIC STRUCTURE THEORY WEBSITE. Available online: https://www.sfu.ca/rst/06tools/index.html.

RIDDEL, A. - BASSET, T.J. - SCHNEIDER, L. - MILLS, H. - YARNEL, A. CONDON, R. - BASSET, J. - DUKE, S. 2019. Common library 1.0: A Corpus of Victorian Novels Reflecting the Population in Terms of Publication Year and Author Gender. Available online: https://arxiv.org/abs/1909.02602.

SKETCH.ENGINE. Available online: https://app.sketchengine.eu/

ZHAO, Y. 2014. L2 Creative Writers' Identities: Their Cognitive Writing Processes and Sense of Empowerment. In: New Writing: International Journal for the Practice and Theory of Cognitive Writing, vol.11, n.3, pp.452-466. ISSN 1479-0726. 
Words: 4250

Characters: 28288 (15,72 standard pages)

Assoc. prof. Inna Livytska, Ph.D.

Post-doctoral research scholar

Department of English Philology and Cross-Cultural Communication

Taras Shevchenko National University of Kyiv

60, Volodymyrska Street

01033 Kyiv

Ukraine

inna.livytska@gmail.com

orcid.org/0000-0002-8295-948X 


\section{APPENDIXES}

Appendix: Pronoun 'I' + Verb combination in the subcorpus 'Victorian Fiction':

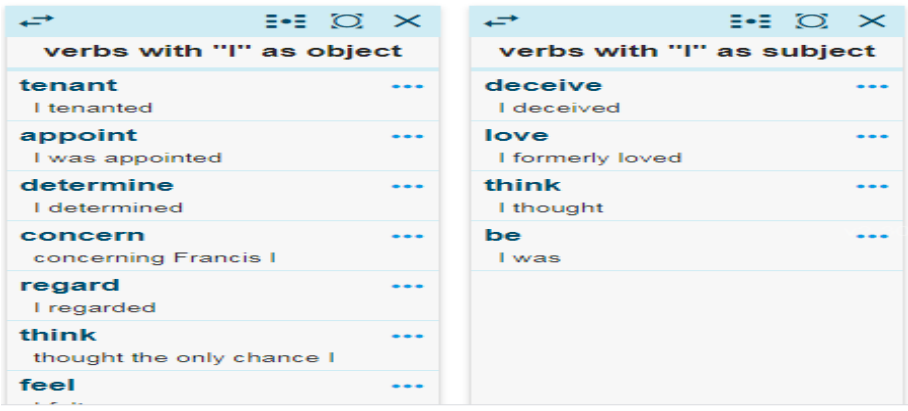

Appendix: Pronoun ' $I$ ' + Verb in Concordance of the subcorpus 'Victorian Fiction' (Sketch.Engine):

\begin{tabular}{|c|c|c|c|}
\hline$\square$ & Left context & KWIC & Right context \\
\hline $1 \square$ & (i) doc\#0 another thought upon her. $</ \mathrm{s}><\mathrm{s}>$ This much & 1 & thought it lay upon my conscience to say, in ju: II \\
\hline $2 \square$ & (i) doc\#2 > With increased violence he exclaimed, 'Have & 1 & deceived myself here too? $\langle/ \mathrm{s}\rangle\langle\mathrm{s}\rangle$ Therese, d $\mid]$ \\
\hline $3 \square$ & (i) doc\#2 insciousness, and, bereaved though I am of all & 1 & formerly loved, be indeed blessed while on ea II \\
\hline $4 \square$ & (i) doc\#4 The wheels move in swifter rotation than those & 1 & was appointed to watch, and to keep this rotati [] \\
\hline $5 \square$ & (i) doc\#5 lismay, when I recognized his livery; at the first & 1 & thought that he meant only to change horses, : / \\
\hline $6 \square$ & (i) doc \#7 e with her; but, prone to be selfish, on my own & I & am still more so. $</ s\rangle\langle s\rangle$ | regret the peculiariti $\mid$ \\
\hline
\end{tabular}

Appendix: General Account of Pronoun Frequency in the subcorpus 'Victorian Fiction' (Sketch.Engine)

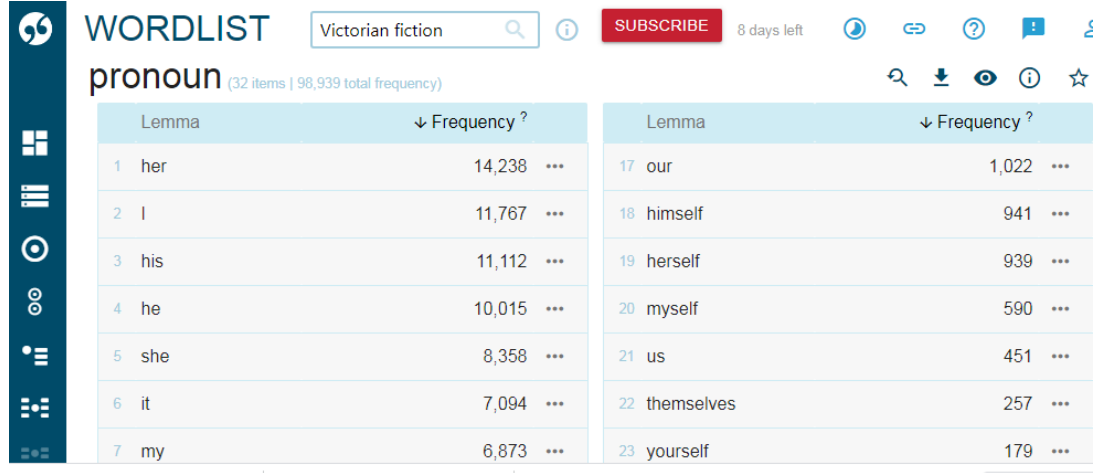

Appendix: Worldlist for lemma 'LOVE' in the subcorpus 'Victorian Fiction' (Sketch.Engine) 


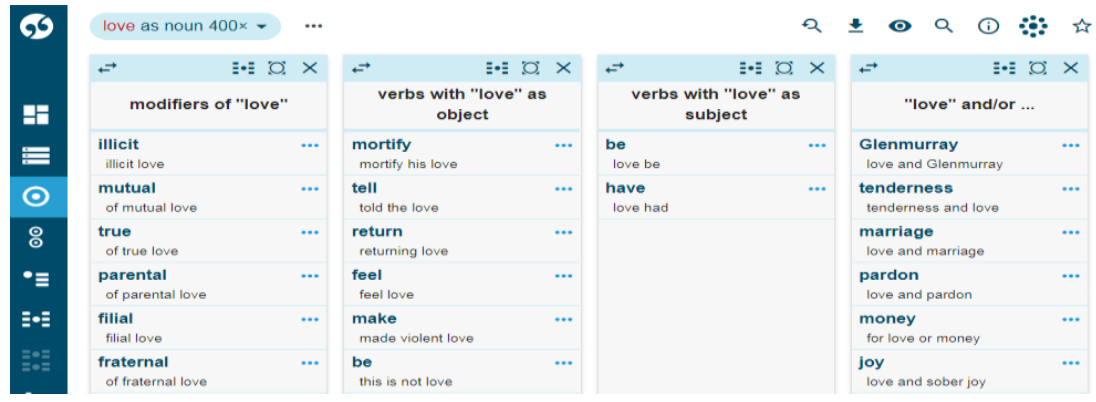

